\title{
Correction to: Strategies for Team Science Success
}

\author{
Kara L. Hall, Amanda L. Vogel, and Robert T. Croyle
}

\section{Correction to: \\ K. L. Hall et al. (eds.), Strategies for Team Science Success, https://doi.org/10.1007/978-3-030-20992-6}

- The published version of the book has missed to include the corresponding authors' e-mail address for chapters 14, 35 and 44 .

- Affiliation correction provided for the author Dr. Milton Eder in chapter 9 has been missed to update in the list of contributors.

- The affiliation detail for the author Dr. Stephen M were published incorrectly in chapter 33. Also, the text in the Abstract section which reads "(cite other chapters in team science book)," was not removed during the copy editing stage.

These errors have been corrected, and the text has been updated in the book.

\section{Chapter 45:}

This chapter was previously published non-open access. It has now been changed to open access under a CC BY 4.0 license and the copyright holder has been updated to "The Author(s)". The book has also been updated with these changes.

\footnotetext{
The updated online version of this book can be found at https://doi.org/10.1007/978-3-030-20992-6 https://doi.org/10.1007/978-3-030-20992-6_9 https://doi.org/10.1007/978-3-030-20992-6_14 https://doi.org/10.1007/978-3-030-20992-6_15 https://doi.org/10.1007/978-3-030-20992-6_33 https://doi.org/10.1007/978-3-030-20992-6_35 https://doi.org/10.1007/978-3-030-20992-6_44 https://doi.org/10.1007/978-3-030-20992-6_45
} 